\title{
WAWASAN KEBANGSAAN: \\ NEGARA PANCASILA SEBAGAI \\ Darul 'Ahdi wa al Syahadah
}

Penulis:

Anita Puji Astutik

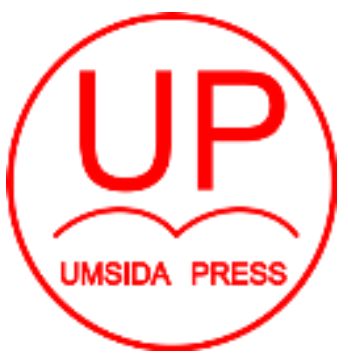

Diterbitkan oleh

UMSIDA PRESS

Jl. Mojopahit 666 B Sidoarjo

ISBN: 978-623-7578-65-9

Copyright $\odot 2019$.

Authors

All rights reserved 
WAWASAN KEBANGSAAN:

NEGARA PANCASILA SEBAGAI

Darul 'Ahdi wa al Syahadah

Penulis :

Anita Puji Astutik

\section{ISBN :}

978-623-7578-65-9

\section{Editor :}

Anita Puji Astutik

\section{Copy Editor :}

Anis Farihah

Design Sampul dan Tata Letak :

Rifa'atus Shoolihah Zamzami

\section{Penerbit :}

UMSIDA Press

\section{Redaksi :}

Universitas Muhammadiyah Sidoarjo

J1. Mojopahit No 666B

Sidoarjo, Jawa TImur

Cetakan pertama, November 2019

(C) Hak cipta dilindungi undang-undang

Dilarang memperbanyak karya tulis ini dengan suatu apapun tanpa ijin tertulis dari penerbit. 


\section{KATA PENGANTAR}

Puji syukur kepada Tuhan Yang Maha Esa, sehingga Buku Wawasan Kebangsaan: Negara Pancasila Sebagai Darul 'Ahdi wa al Syahadah ini dapat disusun dengan baik meskipun perlu penyempurnaan lebih lanjut. Buku ini menjadi pedoman sosialisasi kepada pelajar maupun mahasiswa untuk meningkatkan kesepahaman tentang komitmen Muhammadiyah tentang wawasan kebangsaan.

"Negara Pancasila sebagai Darul 'Ahdi wa al Syahadah" merupakan komitmen Muhammadiyah untuk terus berkiprah membangun dan meluruskan arah Indonesia sebagai Negara Pancasila yang maju, adil, makmur, bermartabat, dan berdaulat menuju peradaban yang utama dalam ridla Allah Subahanu wa Ta'ala. terhadap aktivisme gerakan Mahasiswa.

Belakangan ini, Indonesia diwarnai dengan fenomena radikalisme. Kemandegan suatu ideologi dalam memecahkan masalah yang terjadi merangsang untuk mencari alternatif ideologi lain yang secara empiris dianggap berhasil. Maka tak jarang, kajian-kajian kritis yang kerap 
dilakukan lewat pengujian terhadap pendekatan ideologi atau metodologis tertentu yang diminati.

Hal ini melatarbelakangi perlunya disusun sebuah pedoman sosialisasi sebagai peningkatan kesepahaman tentang wawasan kebangsaan, khususnya mengenai komitmen Muhammadiyah "Negara Pancasila Sebagai Darul "Ahdi wa al Syahadah".

Secara keseluruhan buku ini memuat empat pembahasan yang terdiri atas:

- Relasi Islam dan Negara

Membahas mengenai pandangan terkait dengan relasi konseptual menyangkut agama dan negara, hubungan antara Islam dan politik di era kontemporer.

- Muhammadiyah dan Wawasan kebangsaan

Menjelaskan tentang pengertian wawasan kebangsaan, peran historis Muhammadiyah sebagai bagian integral bangsa Indonesia dan kontribusinya dalam keberlangsungan negara Indonesia serta komitmen Muhammadiyah dalam mengisi kehidupan kebangsaan.

- Negara Pancasila Sebagai Darul 'Ahdi wa al Syahadah Menguraikan secara rinci tentang komitmen Muhammadiyah yang menjadikan Negara Pancasila sebagai Dar al-Syahadah atau negara tempat bersaksi dan 
membuktikan diri dalam membangun kehidupan kebangsaan yang bermakna menuju kemajuan di segala bidang kehidupan sertab pengejawantahan komitemen Muhammadiyah dalam bentuk amal perbuatan.

Ucapan terima kasih kami sampaikan kepada semua pihak yang telah memberikan bahan-bahan tulisan baik langsung maupun tidak langsung. Kritik dan saran sangat diharapkan untuk penyempurnaan buku ini.

Akhirnya kalimat syukur Alhamdulillah kami haturkan kehadirat Allah SWT sehingga penulis dapat menyelesaikan buku pedoman sosialisasi "Wawasan Kebangsaan: Negara Pancasila Sebagai Darul 'Ahdi wa al Syahadah" yang diharapkan dapat memberikan kontribusi positif bagi pembaca dan pemerhati kajian Islam khususnya bagi para pelajar, mahasiswa dan seluruh warga negara Indonesia.

Penulis 


\section{DAFTAR ISI}

KATA PENGANTAR .........................................................

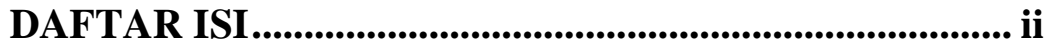

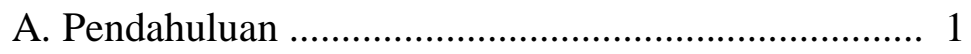

B. Relasi Islam dan Negara ........................................... 4

C. Muhammadiyah dan Wawasan Kebangsaan ................ 6

D. Negara pancasila Sebagai Darul 'Ahdi wa al Syahadah .......................... 16

E. Sosialisasi Negara pancasila Sebagai Darul 'Ahdi wa al Syahadah .......................... 25

Daftar Pustaka ............................................................. 35

Profil Penulis ................................................................ 37 


\section{WAWASAN KEBANGSAAN: \\ NEGARA PANCASILA SEBAGAI DARUL 'AHDI \\ WA AL SYAHADAH}

\section{A. Pendahuluan}

Islam sebagai risalah yang membawa rahmat bagi semesta alam (QS Al-Anbiya: 107). Allah Subhanahu Wa Ta'ala mengutus Nabi Muhammad s.a.w. untuk mendakwahkan ajaran Islam kepada umatnya. Sebagai kesatuan insan muslim di manapun berada berkewajiban menjalankan dan mendakwahkan ajaran Islam yang diperintahkan Allah dan Rasul-Nya sebagai wujud ibadah dan kekhalifahan untuk meraih kebaikan hidup di dunia dan akhirat (QS Adz-Dzariyat: 56; Al-Baqarah: 30, Hud: 61; dan Al-Baqarah: 201). Kewajiban mengemban misi Islam itu tidak pernah selesai dan harus terus dilakukan sebagai perwujudan kesaksian (syuhada 'ala al-nas) sepanjang hayat dalam kehidupan pribadi, keluarga, masyarakat, bangsa, dan ranah kemanusiaan universal.

Islam adalah agama yang universal dan membawa rahmat seluruh alam. Selain sebagai agama, Islam adalah sistem yang menyeluruh, yang menyentuh segala aspek kehidupan. Kaidah dan prinsip-prinsip 
umum yang berkaitan dengan sistem negara juga telah diatur dalam Islam. Al Quran meletakkan kaidah umum yang berkaitan dengan negara dan pemerintahan seperti penegakkan keadilan, penerapan musyawarah, memperhatikan kesamaan, jaminan hak dan kebebasan berpendapat, dan penetapan solidaritas sosial secara komprehensif serta hubungan pemimpin dan rakyatnya seperti hak dan kewajiban timbal balik antara pemimpin dengan rakyatnya. Namun Islam hanya meletakkan kaidah-kaidah umum dan tidak menetapkan bentuk ataupun aturan terperinci yang berkaitan dengan kepemimpinan dan pengelolaan negara. Adapun bentuk ataupun model pemerintahan beserta metode pengelolaannya menjadi ruang lingkup ijtihad dan proses pembelajaran kaum Muslimin dengan memperhatikan aspek kemaslahatan dan menyesuaikan perkembangan zaman.

Komitmen kebangsaan Muhammadiyah tentang Negara Pancasila sebagai Darul Ahdi Wa Syahadah telah secara tegas disusun dan dibahas dalam Muktamar Muhammadiyah ke- 47 di Makasar 2015 yang lalu. Keputusan Muktamar yang tertuang dalam Tanfidz Keputusan Muktamar 
Muhammadiyah ke-47 tersebut kini dibukukan menjadi Negara Pancasila sebagai Darul Ahdi Wa Syahadah yang diterbitkan Penerbit Suara Muhammadiyah pada tahun 2015.

Pandangan Negara Pancasila sebagai Darul Ahdi Wa Syahadah, berangkat dari tiga latar belakang utama. Pertama, adanya kelompok-kelompok atau beberapa elemen masyarakat, terutama masyarakat muslim yang masih mempersoalkan relasi antara Islam dengan negara, dan mempersoalkan negara Indonesia yang berdasarkan Pancasila. Kedua, adanya realitas bahwa sebagai bangsa ini secara ideologis belum merumuskan dengan sangat eksplisit dan membuat satu penjelasan akademik mengenai negara Pancasila itu. Ketiga, ada sebuah realitas dimana masyarakat Islam dianggap sebagai ancaman terhadap negara Pancasila itu.

Terkait dengan tiga realitas inilah kemudian Muhammadiyah perlu membuat suatu pernyataan bahwa secara organisasi Muhammadiyah menerima Pancasila sebagai bentuk ideal, baik yang bersifat filosofi maupun ideologis. Bahkan juga secara konstitusional dalam hal berbangsa dan bernegara. 
Upaya penguatan kajian Negara Pancasila tersebut, sudah mulai dilakukan oleh para elite Muhammadiyah di lingkungan pendidikan agar memperoleh kesepahaman tentang wawasan kebangsaan. Ikhtiar ini telah dirintis oleh Tim Kerja Tindak Lanjut Kerja sama PP Muhammadiyah dan Kemenko PMK dengan membuat bahan pedoman sosialisasi "Pancasila Sebagai Darul 'Ahdi wa al Syahadah". Berdasarkan hal ini, penulis ingin berkontribusi dengan menambahkan bahan pedoman sosialisasi untuk memberikan pemahaman yang lebih dalam tentang komitmen Muhammadiyah dalam peran kebangsaan.

\section{B. Relasi Islam dan Negara}

Diskursus tentang apakah sesungguhnya Islam mewajibkan kaum Muslim untuk membentuk sebuah negara yang secara formal bernama negara Islam sangat menarik dikaji. Sebagian kaum Muslim berpandangan bahwa kewajiban mendirikan negara Islam dengan mengajukan pelbagai dalil dari Al-Qur'an amat penting dilaksanakan. Piagam Madinah juga menjadi rujukan kelompok ini sebagai landasan justifikasi pandangan tentang negara Islam. Pemerintahan Islam di Spanyol pada zaman keemasan Islam di abad pertengahan adalah salah satu 
contoh penerapan negara Islam. Peradaban Islam mampu bertahan lama dengan mengikuti tradisi Islam dari zaman Nabi dan menjadi umat yang toleran.

Berkaitan dengan hal ini, ada tiga pandangan terkait dengan relasi konseptual menyangkut agama dan negara. Pertama, pandangan yang mewajibkan pendirian negara Islam yang tunduk pada syariat Islam. Tokoh yang menjadi ikon kelompok ini adalah Abul A'la al-Maududi. Dalam bukunya tentang khilafah dan kerajaan, al-Maududi berargumen bahwa pentingnya negara Islam dilandasi oleh perintah Al-Qur'an yang menyeru kaum Mukmin untuk taat kepada Allah dan RasulNya serta pemimpin dari kalangan mereka sendiri.(Almaududi, 1988) ; Kedua, pandangan tentang negara sekuler yang memisahkan urusan negara dan agama. Pandangan ini didasarkan pada "doktrin" yang menjadi konsep awal munculnya sekularisme: "Berikan apa-apa yang menajdi hak kaisar dan berikan gereja haknya" (Lewis, 2002); ketiga, pandangan yang menyatakan pentingnya internalisasi nilai-nilai Islam dalam bernegara tanpa harus melabeli suatu negara dengan nama negara Islam. Pandangan ini mengibaratkan dua sisi mata uang. Suatu konsep negara yang mengombinasikan kepentingan 
dan nilai-nilai Islam dalam praktik bernegara tanpa harus menyematkan secara formal nama negara Islam di satu sisi dan di sisi lain juga tidak menjadi negara sekuler (Aziz, 2011).

Hubungan antara Islam dan politik di era kontemporer hanya bisa dimengerti tidak hanya dari dinamika internal Islam yang beragam, tetapi juga dengan menempatkannya dalam perubahan-perubahan politik yang lebih luas. Islamisme bukan semata penolakan terhadap modernitas tetapi bagian dari modernitas itu sendiri. Di Indonesia, masuknya kekuatan- kekuatan Islam ke dalam politik tidak terelakkan dan sudah menjadi bagian yang inheren dalam sejarah. Demokrasi dimaknai sebagai kebebasan untuk mengartikulasikan kepentingan dan identitasnya di ruang publik, peluang Islam untuk terlibat dalam politik sangat besar.

\section{Muhammadiyah dan Wawasan Kebangsaan}

Suatu paham yang menyatukan berbagai suku bangsa dan berbagai keturunan bangsa asing dalam wadah Kesatuan Negara Indonesia merupakan paham kebangsaan bagi bangsa Indonesia. Dalam konsep ini berarti tujuan 
adalah formal yaitu kesatuan dalam arti kesatuan rakyat yang menjadi warga Negara Indonesia ber-Pancasila, maka nasionalisme Indonesia disebut juga dengan nasionalisme Pancasila yaitu kebangsaan yang berdasar nilai-nilai Pancasila (Noor M Bakry, 1994).

Wawasan dapat diartikan sebagai pandangan atau tujuan. Sedangkan kebangsaan adalah ciri-ciri atau identitas yang menandai asal bangsanya, atau golongan suatu bangsa (Badudu-Zain, 2001).

Siswono mengemukakan bahwa, semangat dan wawasan kebangsaan menjadi penting untuk ditumbuhkembangkan, karena rasa kebangsaan sebagai manifestasi dari rasa cinta tanah air, pada giliranya membangkitkan kesadaran kita akan arti mahal dan bernilainya rasa kesatuan dan persatuan bangsa ini (Adi S, 1996). Wawasan kebangsaan meliputi mawas ke dalam dan mawas ke luar. Mawas ke dalam artinya memandang kepada diri bangsa Indonesia sendiri yang memiliki wilayah tanah air yang luas, jumlah penduduk yang banyak, keanekaragaman budaya, yang harus diletakan dalam satu pandangan berdasarkan pada kepentingan bersama sebagai bangsa. Mawas ke luar, yaitu memandang 
terhadap lingkungan sekitar Negara-negara tetangga dan dunia internasional. Bangsa Indonesia harus memiliki integritas dan kredibilitas yang kuat dalam memainkan perannya di dunia internasional sebagai bangsa yang berdaulat dan bermartabat. Dengan demikian, wawasan kebangsaan menjadi penting untuk ditanamkan kepada setiap Warga Negara Indonesia, sehingga wawasan kebangsaan ini harus benar- benar terealisasi dalam kehidupan nyata sehari-hari (Fajar:2009) mengemukakan bahwa hakekat dari wawasan kebangsaan itu sendiri adalah keutuhan Nasional, dalam pengertian cara pandang yang selalu utuh menyeluruh dalam lingkungan nusantara dan demi kepentingan nasional.

Menurut beberapa pendapat di atas wawasan kebangsaan adalah salah satu sikap atau sifat mengenal lebih dekat dan mempelajari bangsanya agar menimbulkan rasa nasionalisme dalam jiwa mereka. Di dalam pendidikan wawasan kebangsaan harus ditanamkan kepada siswa agar siswa dapat menghargai bangsanya dan pahlawannya serta bangga akan bangsanya yaitu Indonesia.

Muhammadiyah merupakan organisasi Islam yang dikenal sebagai gerakan Islam amar ma'ruf nahi munkar, 
yang berbentuk tajdid atau pembaharuan di bidang keagamaan, sosial, ekonomi, kemasyarakatan dan pendidikan. Dalam pengamalannya, Muhammadiyah meyakini Alquran dan Sunnah sebagai sumbernya. Tafsir atas Alquran diturunkan pada tataran praksis dan diterjemahkan menjadi gerakan nyata. Pada saat Muhammadiyah muncul di panggung sejarah, kondisi masyarakat mengalami kerusakan dalam bidang kepercayaan, kebekuan dalam bidang hukum fikih, kemunduran dalam bidang pendidikan, dan kemiskinan rakyat serta hilangnya rasa gotong royong.

Sebagai bagian dari umat Islam dan bangsa Indonesia, sejatinya Muhammadiyah dapat memberikan kontribusi dalam bentuk pemikiran, wacana dan paradigma mengenai politik yang kondusif bagi keberlangsungan negara Indonesia. Dalam bidang politik, Muhammadiyah bergerak sesuai dengan khittahnya sebagai panduan langkah-langkah dalam berjuang. Salah satu khittah perjuangan Muhammadiyah berisi pernyataan tentang Muhammadiyah dan politik.

Dalam Anggaran Dasar Muhammadiyah Bab III pasal 6, dijelaskan bahwa maksud dan tujuan Muhammadiyah 
ialah untuk menegakkan dan menjunjung tinggi Agama Islam sehingga terwujud masyarakat Islam yang sebenarbenarnya (PP. Muhammadiyah, 2005). Masyarakat Islam yang sebenar-benarnya yang tertera dalam Maksud dan Tujuan Muhammadiyah di atas, oleh Pimpinan Pusat Muhammadiyah dimaknai sebagai masyarakat tauhid yang moderat, teladan inklusif dan toleran, solid dan peduli sesama serta mempunyai kesadaran mengemban amanah sebagai wakil Allah di bumi yang bertugas menciptakan kemakmuran.

Muhammadiyah sebagai komponen strategis umat dan bangsa di Negara Republik Indonesia memiliki kewajiban kolektif dan telah berkiprah lebih satu abad untuk mendakwahkan Islam mengajak pada kebaikan, menyuruh pada yang makruf, dan mencegah dari yang munkar sebagaimana misi awal kelahirannya yang terkandung dalam Al-Quran Surat Ali Imran 104. Muhammadiyah berkomitmen untuk menjadikan umat Islam sebagai khayra ummah atau umat terbaik (QS Ali Imran: 110) yang tampil sebagai golongam tengahan (ummatan wasatha) dan berperan sebagai syuhada 'ala al-nas atau saksi bagi kehidupan umat manusia (QS Al-Baqarah: 143), sehingga 
kehadirannya menjadi rahmat bagi semesta alam (QS. AlAnbiya: 107).

Dalam kehidupan kebangsaan, Muhammadiyah dan umat Islam sebagai golongan mayoritas memiliki tanggungjawab besar dan utama untuk menjadikan negara Indonesia sebagai Baldatun Thayyibatun Wa Rabbun Ghafur, yakni negara yang baik dan berada dalam ampunan Allah (QS Saba: 15). Di dalam negara tersebut para penduduknya beriman dan bertaqwa sehingga diberkahi Allah (QS Al-'Araf: 96), mereka membangun negeri ini dengan sabaik-baiknya dan tidak membuat kerusakan (QS Al-Baqarah: 11, 60; Ar-Rum: 41; Al-Qashash: 77). Dengan demikian Muhammadiyah berkomitmen untuk terus berjuang memproyeksikan Indonesia menjadi Negara Pancasila yang maju, adil, makmur, bermartabat, dan berdaulat dalam lindungan Allah SWT.(PP.Muhammadiyah, 2015)

Muhammadiyah sejak awal perjuangan kemerdekaan hingga berdirinya Negara Kesatuan Republik Indonesia (NKRI) senantiasa berkomitmen untuk menjaga dan menegakkan Negara yang berdasarkan Pancasila dan UUD 1945. Sikap itu sesuai dengan cita-cita nasional 
sebagaimana dirumuskan oleh para pendiri bangsa ketika itu. Bahkan, salah satu tokoh Muhammadiyah Ki Bagus Hadikusumo (Ketua Pengurus Besar Muhammadiyah periode 1942-1953), telah terlibat aktif dalam penyusunan konstitusi negara Undang-Undang dasar 1945 yang terdiri dari pembukaan (muqaddimah) dan batang tubuh konstitusi ( Nur Fuad, 2012). Tokoh Muhammadiyah lainnya yang menjadi pemeran dalam berdirinya bangsa dan juga menghadirkan pilar kebangsaan diantaranya adalah Kahar Muzakir, Ir. Juanda, Mr. Kasman Singodimedjo, bahkan Ir. Soekarno pun adalah salah satu tokoh Muhammadiyah dan masih banyak lagi.

Hal ini juga telah termaktub dalam pedoman hidup Islami warga Muhammadiyah tentang kehidupan dalam berbangsa dan bernegara yang berbunyi: Warga Muhammadiyah perlu mengambil bagian dan tidak boleh apatis (masa bodoh) dalam kehidupan politik melalui berbagai saluran secara positif sebagai wujud bermuamalah sebagaimana dalam bidang kehidupan lain dengan prinsipprinsip etika / akhlak Islam dengan sebaik-baiknya dengan tujuan membangun masyarakat utama yang diridhai Allah SWT (Amin Abdullah, dkk, 2015) 
Haedar Nasir dalam siaran pers menyatakan bahwa dalam kehidupan kebangsaan Muhammadiyah sejak awal berjuang untuk pengintegrasian keislaman dan keindonesiaan. Muhammadiyah dan umat Islam merupakan bagian integral bangsa dan telah berkiprah dalam membangun lndonesia sejak pergerakan kebangkitan nasional hingga era kemerdekaan. Negara Pancasila yakni Negara Kesatuan Republik Indonesia yang berdasarkan Pancasila adalah hasil konsensus para pendiri bangsa dan seluruh komponen bangsa Indonesia yang harus ditegakkan dan dijunjung tinggi serta dibangun menjadi negeri yang bersatu, berdaulat, adil, dan makmur dalam lindungan Allah Swt (Haedar Nasir, 2017).

Seluruh warga dan komponen bangsa tidak boleh keluar dari kesepakatan, namun sebagai wujud perjanjian yang luhur bangsa dan negara Republik Indonesia, sekaligus membangunnya secara sungguh-sungguh menjadi negara dan bangsa berkemajuan di segala bidang kehidupan. Muhammadiyah dalam kehidupan kebangsaan maupun kemanusiaan universal berdasarkan pada pandangan Islam berkemajuan menegaskan komitmen untuk terus berkiprah menyemaikan benih-benih kebenaran, kebaikan, kedamaian, 
keadilan, kemaslahatan, kemakmuran, dan keutamaan hidup secara dinamis menuju peradaban yang utama.

Peran Muhammadiyah dan para tokohnya dalam mengemban misi Islam berkemajuan berlanjut dalam kiprah kebangsaan lahirnya Negara Indonesia Merdeka pada 17 Agustus 1945. Muhammadiyah melalui para pemimpinnya terlibat aktif dalam usaha-usaha kemerdekaan. Setelah Indonesia merdeka, pada berbagai periode pemerintahan hingga periode reformasi, pengabdian Muhammadiyah terhadap bangsa dan negera terus berlanjut. Khidmat kebangsaan ini lahir dari pesan ajaran Islam yang berkemajuan dan didorong oleh keinginan yang kuat agar Indonesia mampu melangkah ke depan menjadi negara dan bangsa yang unggul di segala bidang kehidupan sejalan dengan cita-cita kemerdekaan. Kiprah dan pengkhidmatan Muhammadiyah sepanjang lebih satu abad itu merupakan bukti bahwa Muhammadiyah ikut berkorban, dan memiliki saham yang besar dalam usaha-usaha kemerdekaan dan membangun Negara Indonesia. Karenanya Muhammadiyah berkomitmen untuk terus berkiprah membangun dan meluruskan arah Indonesia sebagai Negara Pancasila yang maju, adil, makmur, bermartabat, dan berdaulat menuju 
peradaban yang utama dalam ridla Allah Subahanu wa Ta'ala (PP Muhammadiyah, 2015).

Pengurus Besar Muhammadiyah dalam amanatnya kepada segenap kaum muslimin terutama anggota dan keluarga Muhammadiyah seluruh Indonesia, dalam rangka menyambut satu tahun kemerdekaan Indonesia, 17 Agustus 1946, menyampaikan agar tetap berjuang demi tegaknya NKRI dan Agama Islam. Disamping memperbanyak amal dan melangsungkan amalan-amalan Muhammadiyah, seluruh anggota Muhammadiyah harus turut bekerja dan berjuang untuk meluhurkan serta menegakkan agama Islam dan negara Republik Indonesia (Imron Nasri, 2012).

Muhammadiyah dengan pandangan Islam Berkemajuan dalam kehidupan berbangsa dan bernegara senantiasa berusaha untuk selalu bisa mempercayakan nilainilai ke-Islaman dan ke-Indonesiaan. Muhammadiyah dan umat islam adalah bagian integral dari bangsa Indonesia yang memiliki peran historis yang menentukan sejak sebelum kemerdekaan hingga sesudah kemerdekaan. Muhammadiyah juga telah dan akan terus memberikan sumbangsih yang besar pada upaya mencerdaskan dan memajukan kehidupan berbangsa dan bernegara serta lebih 
mengembangkan moral politik dalam islam yang berwawasan kebangsaan di tengah pergulatan ideologi Indonesia dan dunia.

\section{Negara Pancasila Sebagai Darul 'Ahdi wa Al Syahadah}

Muhammadiyah memandang bahwa Negara Kesatuan Republik Indonesia (NKRI) yang diproklamasikan 17 Agustus 1945 adalah Negara Pancasila yang ditegakkan di atas falsafah kebangsaan yang luhur dan sejalan dengan ajaran Islam. Sila Ketuhanan Yang Maha Esa, Kemanusiaan yang adil dan beradab, persatuan Indonesia, Kerakyatan yang dipimpim oleh hikmat kebijaksanaan dalam permusyawaratan/perwakilan, dan Keadilan sosial bagi seluruh rakyat Indonesia; secara esensi selaras dengan nilainilai ajaran Islam dan dapat diisi serta diaktualisasikan menuju kehidupan yang dicita-citakan umat Islam yaitu Baldatun Thayyibatun Wa Rabbun Ghafur. Negara Pancasila yang mengandung jiwa, pikiran, dan cita- cita luhur sebagaimana termaktub dalam Pembukaan UUD 1945 itu dapat diaktualisasikan sebagai Baldatun Thayyibatun Wa Rabbun Ghafur yang berperikehidupan maju, adil, makmur, bermartabat, dan berdaulat dalam naungan ridla Allah SWT. 
Negara Pancasila merupakan hasil konsensus nasional (dar al-'ahdi) dan tempat pembuktian atau kesaksian (dar alsyahadah) untuk menjadi negeri yang aman dan damai (dar alsalam) menuju kehidupan yang maju, adil, makmur, bermartabat, dan berdaulat dalam naungan ridla Allah SWT. Pandangan kebangsaan tersebut sejalan dengan cita-cita Islam tentang negara idaman "Baldatun Thayyiabtun Wa Rabbun Ghafur", yaitu suatu negeri yang baik dan berada dalam ampunan Allah. Negara ideal itu diberkahi Allah karena penduduknya beriman dan bertaqwa (QS Al-A'raf: 96), beribadah dan memakmurkannya (QS Adz-Dzariyat: 56; Hud: 61), menjalankan fungsi kekhalifahan dan tidak membuat kerusakan di dalamnya (QS Al-Baqarah: 11, 30), memiliki relasi hubungan dengan Allah (habluminallah) dan dengan sesama (habluminannas) yang harmonis (QS Ali Imran: 112), mengembangkan pergaulan antar komponen bangsa dan kemanusiaan yang setara dan berkualitas taqwa (QS Al-Hujarat: 13), serta menjadi bangsa unggulan bermartabat khyaira ummah (QS Ali Imran: 110) (PP Muhammadiyah, 2015).

Negara Indonesia yang penduduknya mayoritas Muslim tersebut dalam konteks keislaman dan 
keindonesiaan harus terus dibangun menjadi Negara Pancasila yang Islami dan berkemajuan menuju peradaban utama bagi seluruh rakyat. Pancasila sebagai dasar Negara Republik Indonesia adalah ideologi negara yang mengikat seluruh rakyat dan komponen bangsa. Pancasila bukan agama, tetapi substansinya mengandung dan sejalan dengan nilai-nilai ajaran Islam, yang menjadi rujukan ideologis dalam kehidupan kebangsaan yang majemuk.

Dengan demikian dapat dinyatakan bahwa Pancasila itu Islami karena substansi pada setiap silanya selaras dengan nilai-nilai ajaran Islam. Dalam Pancasila terkandung ciri keislaman dan keindonesiaan yang memadukan nilainilai ketuhanan dan kemanusiaan (humanisme religius), hubungan individu dan masyarakat, kerakyatan dan permusyawaratan, serta keadilan dan kemakmuran. Melalui proses integrasi keislaman dan keindonesiaan yang positif itu maka umat Islam Indonesia sebagai kekuatan mayoritas dapat menjadi uswah hasanah dalam membangun Negara Pancasila menuju cita-cita nasional yang sejalan dengan idealisasi Baldatun Thayyibatun wa Rabbun Ghafur.

Segenap umat Islam termasuk di dalamnya Muhammadiyah harus berkomitmen menjadikan Negara 
Pancasila sebagai Dar al-Syahadah atau negara tempat bersaksi dan membuktikan diri dalam membangun kehidupan kebangsaan yang bermakna menuju kemajuan di segala bidang kehidupan. Dalam Negara Pancasila sebagai Darus Syahadah, umat Islam harus siap bersaing (fastabiqul khairat) untuk mengisi dan memajukan kehidupan bangsa dengan segenap kreasi dan inovasi yang terbaik. Dalam hal ini Muhammadiyah sebagai komponen strategis umat dan bangsa mempunyai peluang besar untuk mengamalkan etos fastabiqul khairat itu dan tampil menjadi a leading force atau kekuatan yang berada di garis depan untuk mengisi dan memimpin Negara Pancasila menuju kehidupan kebangsaan yang maju, adil, makmur, bermartabat, dan berdaulat sejajar dengan negara-negara lain yang telah maju dan berperadaban tinggi (PP Muhammadiyah, 2015).

Muhammadiyah sebagai kekuatan strategis umat dan bangsa berkomitmen untuk membangun Negara Pancasila dengan pandangan Islam yang berkemajuan. Islam yang berkemajuan menyemaikan benih-benih kebenaran, kebaikan, kedamaian, keadilan, kemaslahatan, kemakmuran, dan keutamaan hidup secara dinamis bagi seluruh umat manusia. Islam yang menjunjung tinggi kemuliaan manusia 
baik laki-laki maupun perempuan tanpa diksriminasi. Islam yang menggelorakan misi anti perang, anti terorisme, anti kekerasan, anti penindasan, anti keterbelakangan, dan anti terhadap segala bentuk pengrusakan di muka bumi seperti korupsi, penyalahgunaan kekuasaan, kejahatan kemanusiaan, eksploitasi alam, serta berbagai kemungkaran yang menghancurkan kehidupan. Islam yang secara positif melahirkan keutamaan yang memayungi kemajemukan suku bangsa, ras, golongan, dan kebudayaan umat manusia di muka bumi.

Dengan pandangan Islam yang berkemajuan Muhammadiyah bertekad menjadikan Negara Indonesia sebagai Negara Pancasila yang berkemajuan. Muhammadiyah berjuang di Negara Pancasila menuju Indonesia Berkemajuan sesuai dengan Kepribadiannya yaitu:

(1) Beramal dan berjuang untuk perdamaian dan kesejahteraan;

(2) Memperbanyak kawan dan mengamalkan ukhuwah Islamiyah;

(3) Lapang dada, luas pemandangan dengan memegang teguh ajaran Islam; 
(4) Bersifat keagamaan dan kemasyarakatan;

(5) Mengindahkan segala hukum, undang-undang, peraturan, serta dasar dan falsafah negara yang sah;

(6) Amar ma'ruf nahi mungkar dalam segla lapangan serta menjadi contoh teladan yang baik;

(7) Aktif dalam perkembangan masyarakat dengan maksud islah dan pembangunan sesuai dengan ajaran Islam;

(8) Kerjasama dengan golongan Islam mana pun juga dalam usaha menyiarkan dan mengamalkan agama Islam, serta membela kepentingannya;

(9) Membantu Pemerintah serta bekerjasama dengan golongan lain dalam memelihara dan membangun negara untuk mencapai masyarakat yang Islam yang sebenarbenarnya; dan

(10) Bersifat adil serta korektif ke dalam dan ke luar dengan bijaksana (PP Muhammadiyah, 2015).

Muhammadiyah sebagai Gerakan Islam menyadari sepenuhnya bahwa Negara Indonesia merupakan tempat menjalankan misi dakwah dan tajdid untuk terwujudnya masyarakat Islam yang sebenar-benarnya. Muhammadiyah bersama komponen umat Islam dan bangsa Indonesia 
lainnya berjuang dalam gerakan kebangkitan nasional menuju kemerdekaan dan berperan aktif dalam mendirikan Negara Republik Indonesia yang diproklamasikan pada tanggal 17 Agustus 1945.

Sebagaimana terkandung dalam butir kelima Matan Keyakinan dan Cita-cita Hidup Muhammadiyah (MKCH) tahun 1969, sebagai suatu kesyukuran serta wujud tanggungjawab keagamaan dan kebangsaan "Muhammadiyah mengajak segenap lapisan bangsa Indonesia yang telah mendapat karunia Allah berupa tanah air yang mempunyai sumber-sumber kekayaan, kemerdekaan bangsa dan Negara Republik Indonesia yang berdasar Pancasila dan Undang-Undang Dasar 1945, untuk berusaha bersama-sama menjadikan suatu negara yang adil makmur yang diridhai Allah Subhanahu wata'ala: "BALDATUN THAYYIBATUN WA RABBUN GHAFUR”.

Seiring dengan faham Muhammadiyah yang bercorak praksis, maka komitmen wawasan kebangsaan Muhammadiyah tersebut diejawantahkan dalam bentuk amal perbuatan (with action). Hal ini seperti disinyalir oleh Buya Syafi'i Maarif yang menyatakan bahwa 
Muhammadiyah tampak menonjol sebagai gerakan amal (Syafi'i Maarif, 1997). Wawasan kebangsaan ini harus benar- benar terealisasi dalam kehidupan nyata sehari-hari. Karena pada hakekatnya wawasan kebangsaan merupakan cara pandang yang selalu utuh menyeluruh dalam lingkungan nusantara dan demi kepentingan nasional.

Menurut pandangan Ahmad Dahlan, bahwa betapapun bagus program itu, ia tidak akan mencapai tujuan apapun kecuali jika ia praktikkan (Achmad Jainuri, 2002). Sejak berdiri, Muhammadiyah telah membangun infrastruktur bangsa yang berbentuk filantropi. Hal tersebut berbasis pada komitmen Muhammadiyah untuk membentuk kesalehan religius sebagai kunci kesatuan bagi kemakmuran bangsa. Gerakan-gerakan yang dilakukan Muhammadiyah diprioritaskan untuk mengembangkan kebajikan kemanusiaan dalam kehidupan sosial, ekonomi dan politik bagi kepentingan publik. Berbagai layanan Muhammadiyah sebagai diversifikasi dakwah yang bersifat kemanusiaan, diantaranya LAZIZMU dan MDMC.

LAZIZMU dan MDMC merupakan dua diantara gerakan sosial Muhammadiyah yang secara praksis ikut serta dalam mewujudkan masyarakat Indonesia yang aman 
dan sejahtera, sebagaimana dalam ciri kepribadian Muhammadiyah yang kesembilan; Membantu pemerintah serta bekerjasama dengan golongan lain dalam memelihara dan membangun Negara mencapai masyarakat adil dan makmur yang diridlai Allah.

LAZISMU merupakan gerakan Zakat, Infaq dan Shadaqah Muhammadiyah yang amanah, profesional, transparan, dan produktif sesuai dengan syariat Islam dan kemanusiaan dalam rangka meningkatkan kesejahteraan dan kemaslahatan umat. Dalam menjalankan tugas dan fungsinya, LAZIZMU harus berpedoman sesuai dengan syariat Islam, mulai dari tata cara perekrutan pegawai hingga tata cara pendistribusian dana ZIZKA (PP.Muhammadiyah, 2015).

Dalam menguatkan komitmennya untuk visi kemanusiaan yang diterjemahkan ke dalam amal nyata, Muhammadiyah telah memiliki Lembaga Penanggulangan Bencana Pimpinan Pusat Muhammadiyah yang dikenal dalam bahasa inggris "Muhammadiyah Disaster Management Center" atau disingkat MDMC. Lembaga ini dirintis tahun 2007 dengan nama "Pusat Penanggulangan Bencana" yang kemudian dikukuhkan menjadi lembaga 
yang bertugas mengkoordinasikan sumberdaya Muhammadiyah dalam kegiatan penanggulangan bencana oleh Pimpinan Pusat Muhammadiyah pasca Muktamar tahun 2010 .

Penanggulangan bencana adalah bagian dari nafas pergerakan Muhammadiyah sejak pendiriannya di tahun 1912 yang lalu. Komitmen ini telah diwujudkan baik dalam norma organisasi maupun dalam wujud nyata gerakan dengan berbagai karya inovatifnya sebagai pengusung gerakan Islam Berkemajuan. Berdirinya Majelis Penolong Kesengsaraan Oemoem (PKO) sebagai perangkat pelaksana misi persyarikatan di periode awal berdirinya organisasi, kemudian melahirkan berbagai varian aktualisasi ajaran Islam yang terus mengusahakan amalan terbaiknya dalam pemecahkan masalah kemanusiaan (PP.Muhammadiyah, 2015).

\section{E. Sosialisasi Negara Pancasila Sebagai darul 'Ahdi wa Al Syahadah}

Bukti komitmen Muhammadiyah terhadap bangsa dan negara ini sudah selayaknya difahami oleh semua khalayak khususnya pelajar dan mahasiswa Muhammadiyah 
sebagai penerus organisasi. Oleh karena itu perlu dilaksanakan sosialisasi di berbagai lembaga pendidikan melalui seminar, diskusi dan dialog kebangsaan untuk meningkatkan pemahaman tentang kesepahaman negara Indonesia dan Pancasila sekaligus membentengi diri agar tidak yang menolak Dasar Negara Pancasila dan sistem Negara Pancasila dengan mendirikan sistem Negara Islam.

Tim Kerja Tindak Lanjut Kerja sama dengan PP Muhammadiyah dan Kemenko PMK menganalisa, ada 3 alasan yang dikemukakan oleh para penentang Pancasila dan sistem Negara Pancasila;1). Alasan teologis 2). Alasan empiris, dan 3). Alasan historis. Hal ini diperjelas dalam bahan edukasi untuk mensosialisasikan peran Muhammadiyah dalam kebangsaan dengan judul "Negara Pancasila Sebagai Darul 'Ahdi wa al Syahadah”, berikut ini: 


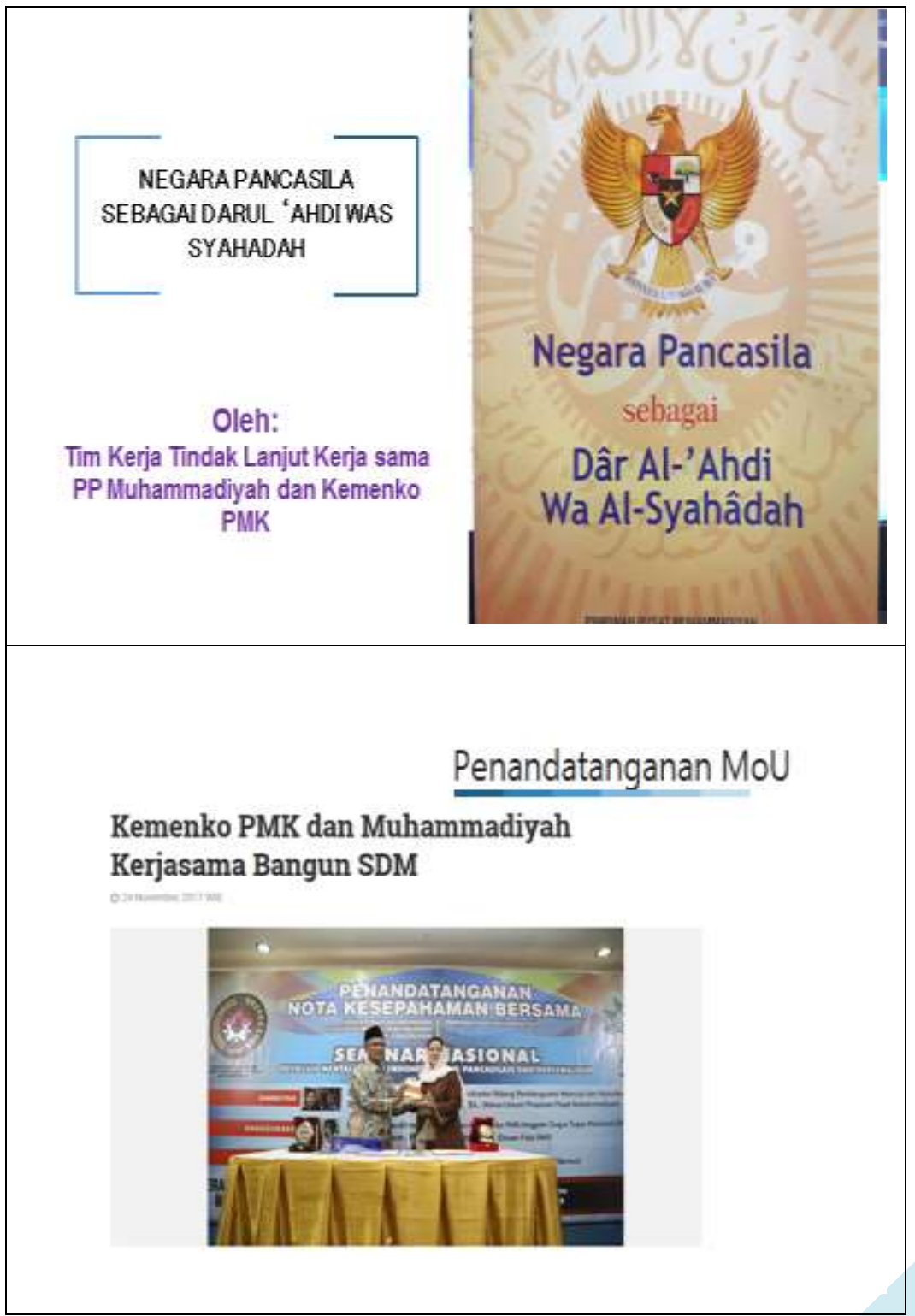

WAWASAN KEBANGSAAN:

NEGARA PANCASILA SEBAGAI DARUL 'AHDI WA AL SYAHADAH 


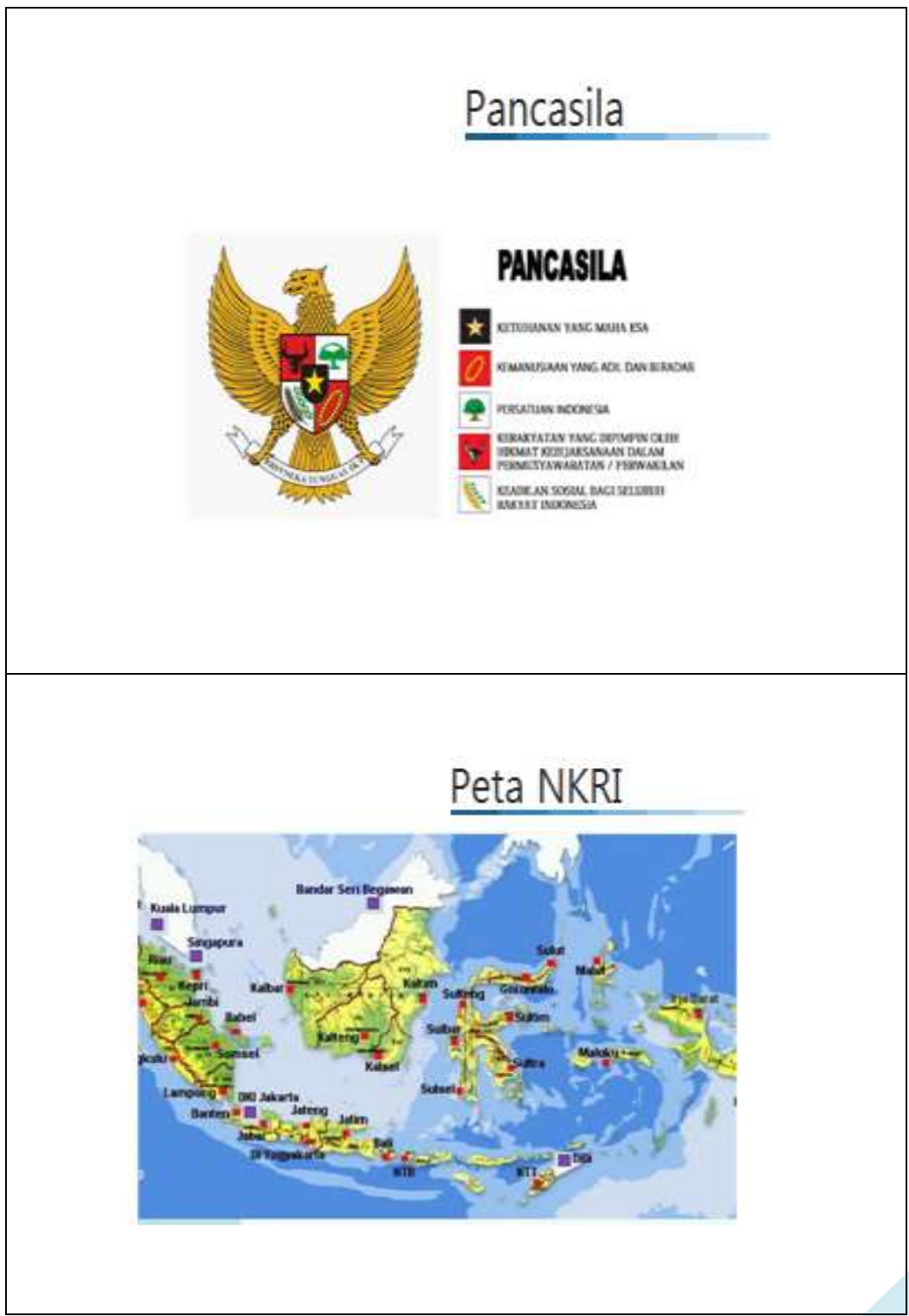

WAWASAN KEBANGSAAN: NEGARA PANCASILA SEBAGAI DARUL 'AHDI WA AL SYAHADAH 


\section{Pendahuluan}

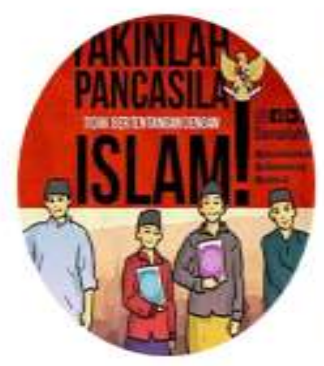

Indonesia yang berdasarkan Pancasila dan UUD 1945 merupakan bentuk ideal yang tepat untuk bangsa dan masyarakat Indonesia yang majemuk.

Secara substansi, Pancasila merupakan kristalisasi nilai-nilai utama yang terakar dalam budaya bangsa Indonesia dan nilai-nilai universal agama. Karena itu, Pancasila tidak bertentangangan dengan agama Islam, bahkan dithat dari isi dan prinsip-prinsipnya, sebagaimana tersebut dalam sila-silanya, Pancasila adalah dasar negara yang islami karena bersesuaian dan tidak bertentangan dengan ajaran Islam

\section{Negara Pancasila : Darul ahdi wa syahadah}

Bagi Muhammadiyah, sesuai keputusan Muktamar 47 tahun 2015, Negara Pancasila tidak hanya ideal dan islami, tetapi juga merupakan daut ahdi wa syahadah, Indonesia adalah negara perjanjan dan kesepakatan (darul ahdi) para pendir bangsa yang harus dipertahankan.

Indonesia adalah dar al-syahadah; rumah bagi seluruh warga negara dan tempat untuk berkhidmad dan membuktikan din bahwa dengan Pancasila, Indonesia dan ajaran Islam, Indonesia akan mampu mewujudkan cita-citanya sebagai negara yang merdeka, bersatu, berdaulat, adil dan makmur

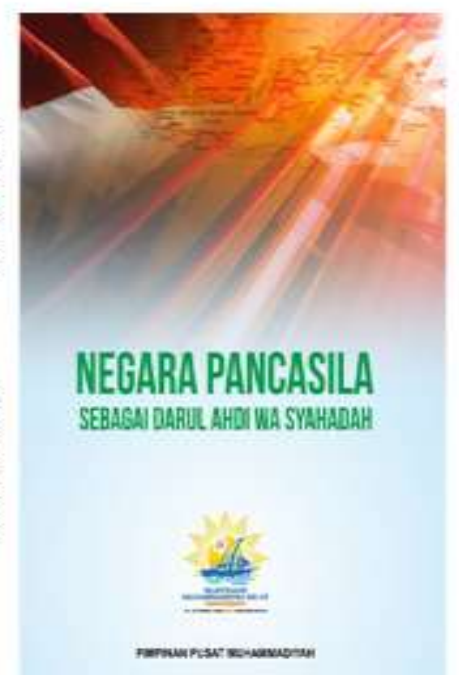

WAWASAN KEBANGSAAN: NEGARA PANCASILA SEBAGAI DARUL 'AHDI WA AL SYAHADAH 


\section{Ukhuwah Dalam Kehidupan}

- Ada 3 jenis persaudaraan dalam kehidupan 1). Ukhuwah Islamiyah (persaudaraan sebagai sesama Muslim), 2). Ukhuwah wathaniyah (persaudaraan sebagai sesama anak bangsa), dan 3). Ukhuwah bashariyah / insaniyah (persaudaraan sebagai sesama manusia).

- Indonesia memiliki 261 juta penduduk, 714 suku, >1.100 bahasa lokal, 34 provinsi, 415 Kabupaten, 93 Kota, 6524 Kecamatan dan 76632 kelurahan/Desa merupakan anugerah Allah Swt.

- Karena itu ukhuwah sangat penting dan strategis bagi persatuan dan keutuhan Negara Kesatuan Republik Indonesia.

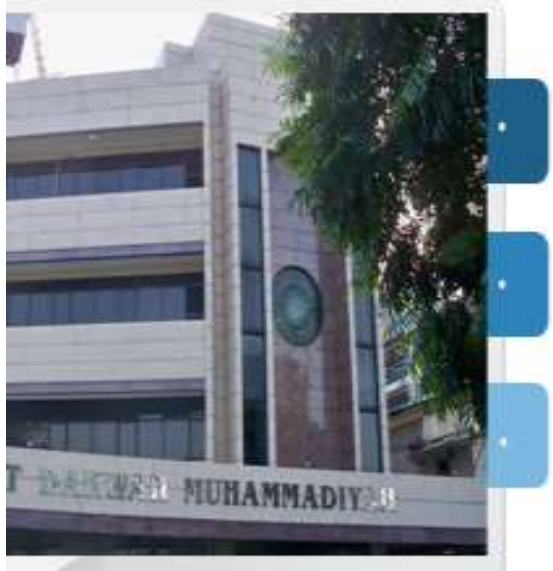

\section{Pengamalan Sila 1} dalam Muhammadiyah

Gerakan berkethhanan, pengamaian nilai agama dalam kehidupan keseharian diri, kehuarga, masyarakat, organisasi dan warga Mubammadival:

Pendidikan dan dakwah keagamaan diakukan secara masif dan simultan, untuk mengukuhkan nilai keimanan;

Meminimalisir Syirik dikalangan kaum Muslimin untuk menguluhkkan aqidah, implementasi dari tafsir Ketuhanan Yang Maha Esa.

WAWASAN KEBANGSAAN: NEGARA PANCASILA SEBAGAI DARUL 'AHDI WA AL SYAHADAH 


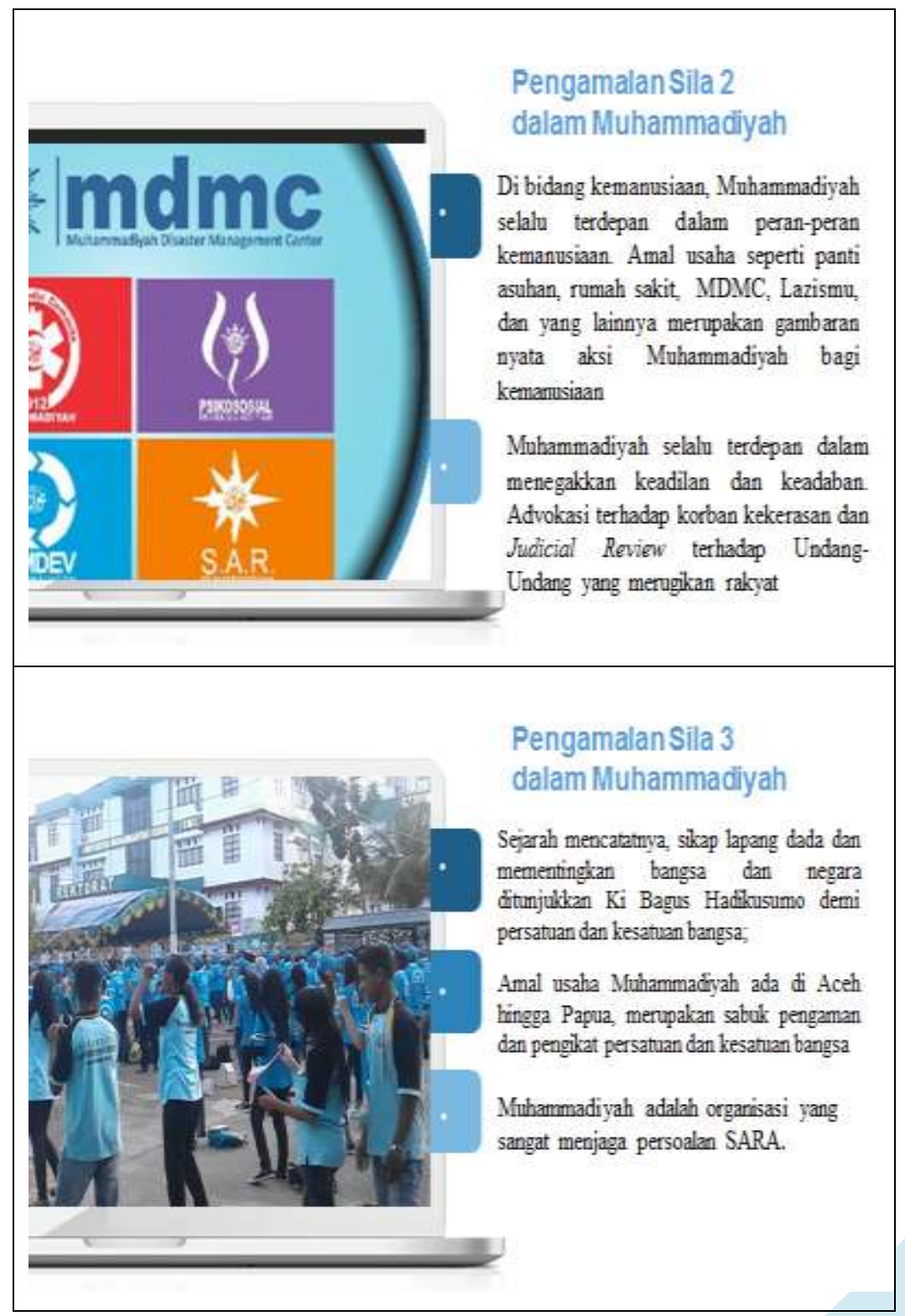

WAWASAN KEBANGSAAN: 


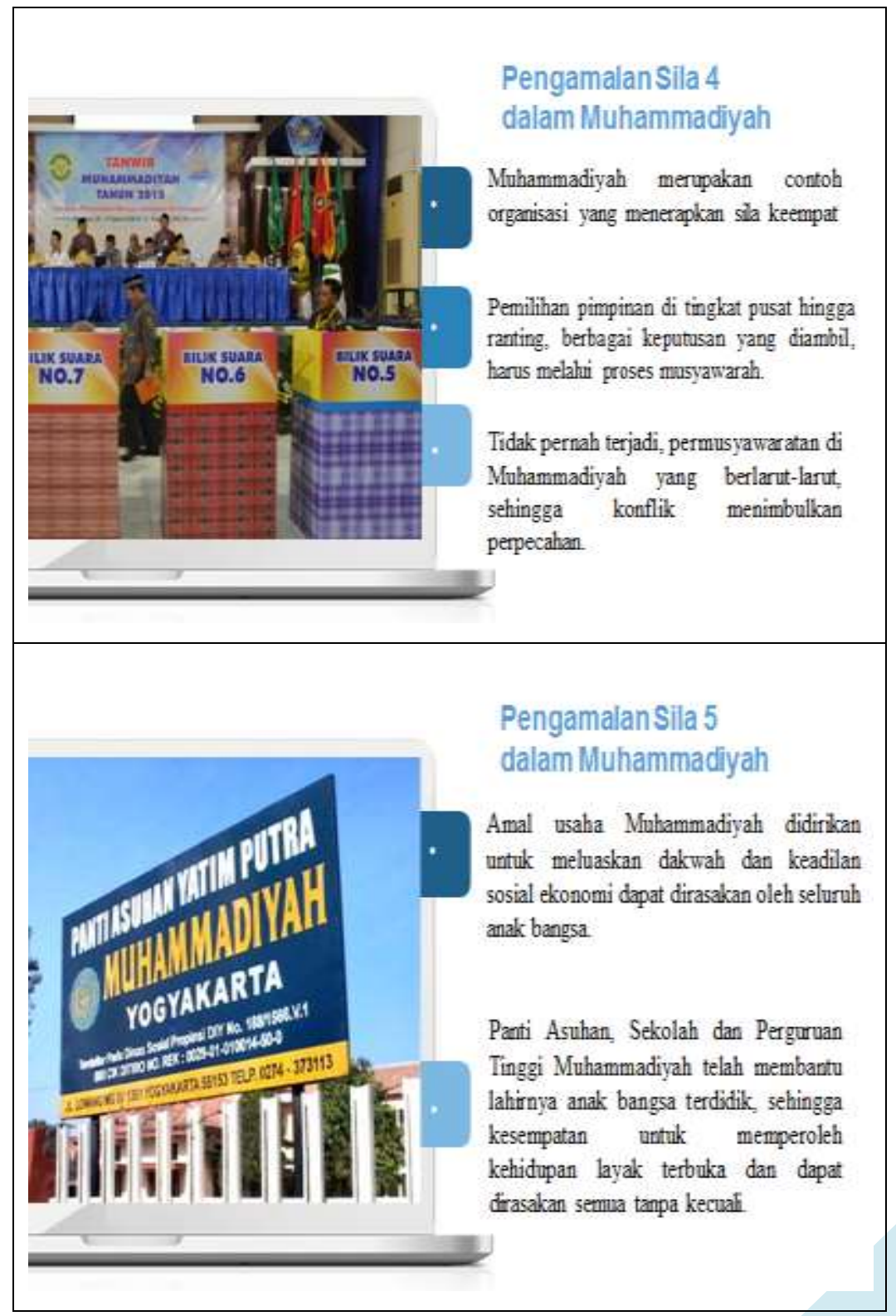

WAWASAN KEBANGSAAN: 


\section{Pedoman Hidup Islami Warga Muhammadiyah dalam kehidupan berbangsa dan bernegara (1)}

- Warga Muhammadivah perlu mengambil bagian dan tidak boleh apatis (masa bodoh) dalam kehidupan politik melalui berbagai saluran secara positf sebagai wujud bermuamalah sebagaimana dalam bidang kehidupan lain dengan prinsip-prinsip etikalakhlaq Islam dengan sebaik-baiknya dengan tujuan membangun masyarakat Islam yang sebenar-benarnya.

- Beberapa pinsip dal am berpolitik harus ditegakkan dengan sejujur-jujumya dan sesungguhsungguhnya yaitu menunaikan amanat dan tidak bolefi menghianati amianat, menegakkan keadilan, hukum, dan kebenaran, ketaatan kepada pemimpin sejauh sejalan dengan perintah Allah dan Rasul, mengemban risalah Islam, menunaikan amar ma ruf, nahi munkar, dan mengajak orang untuk beriman kepada Allah, mempedomani Al-Quran dan Sunnah, mementingkan kesatuan dan persaudaraan umat manusia, menghormati kebebasan orang lain, menjauhi fitnah dan kerusakan, menghormati hak hidup orang lain, tidak berhianat dan melakukán kezaliman, tidak mengambi hak orang lain bentomba dalam kebaikan, bekerjasama dalam kebaikan dan ketaqwaan serta tidak bekerjasama (konspirasi] dalam melakukan dosa dan permusuhan, memelihara hubungan baik antara pemimpin dan warga. memelihara keselamatan umum, hidup berdampingan dengan bak dan damaj, tidak melakukan fasad dan kemunkaran, mennentingkan ukhuwah Islamijah, dan prinsip-prinsip lainnya yang maslahat, ihsan, dan ishlah.

\section{Pedoman Hidup Islami Warga Muhammadiyah dalam kehidupan berbangsa dan bernegara (2)}

- Berpolitik dalam dan demi kepentingan umat dan bangsa sebagai wujud ibadah kepada Allah dan ishlah serta ihsan kepada sesama, dan jangan mengorbankan kepentingan yang lebih luas dan utama itu demi kepentingan dri sendiri dan kelompok yang sempit.

- Para politisi Muhammadivah berkewaiban menunjukkan keteladanan diri (uswah hasanah) yang jujur, benar, dan adil serta menjaunkan diri dari perilaku politik yang kotor, membawa fitnah, fasad (kerusakan], dan hanya mementingkan dri sendiri.

- Berpolitik dengan kesalihan, sikap positif, dan memiliki cita-cita bagi terwujudnya masyarakat islam yang sebenar-benarnya dengan fungsi amăr ma'rứ dan nahi munkar yang tersistem dalam satu kesatuan imamah yang kokoh.

- Menggalang silaturahmi dan ukhuwah antar politisi dan kekuatan politik yang digerakkan oleh para politisi Muhammadiyah secara cerdas dan dewasa

WAWASAN KEBANGSAAN:

NEGARA PANCASILA SEBAGAI DARUL 'AHDI WA AL SYAHADAH 


\section{Mengapa Pancasila masih di tentang?}

\section{1}

Dalam realitasnya mash banyak masyarakat, termasuk sebagian warga Muhammadirah, yang menolak Daser Negara Parcasila dan sistem Negara Pancasila dengan mendrikan sistem Negara Islam.

\section{2}

Ada 3 alasan yang dikemukakan oleh para penentang Pancasla dan sistem Negara Pancasia -1). Allasun teologis yaitu mereka yang berpandangan dan berkeyakinan bahwa Pancasila adalah thaghut dan sistem negara Pancasia adalah kafir. 2). Alasou empiris bahwa banyak negara Islam yang maju, adil, dan makmur sedangkan Indonesia yang berdasarkan Pancaska justeru miskin, terbelakang, tidak atil dan sebagainja. 3). Alasun histonis bahwa umat Islam pernah meraih kejayaan pada abad Pertengahan di bawah sistem Islam dan Khaifah.

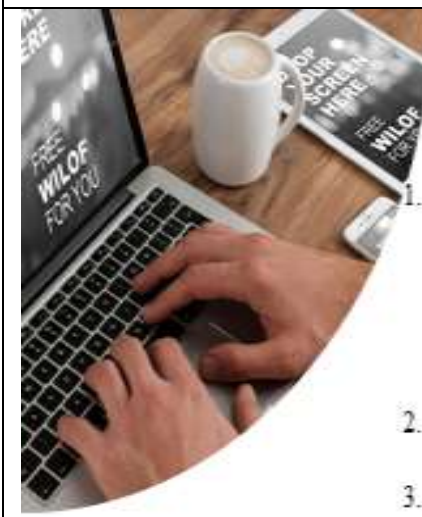

\section{Solusinya}

Perlu adanya sosialisasi empat Pilar kebangsaan yakni : 1). Pancasila adalah Dasar dan Ideologi Negara, 2). UUD NRI tahun 1945 sebagai konstitusi negara dan ketetapan MPR, 3). NKRI sebagai bentuk negara dan 4). Bhineka Tunggal Ika sebagai semboyan negara bagi seluruh rakyat Indonesia, secara berkelanjutan

2. Harus terus digalakkan seminar, diskusi, dialog tentang kebangsaan yang terus menerus

3. Pengamalan Pancasila dalam kehidupan berbangsa dan bernegara

4. Adanya keteladanan dari para elit; pemimpin formal maupun formal dalam pengamalan Pancasila. 


\section{Daftar Pustaka}

Aziz, Abdul. Chiefdom Madinah: Salah paham Negara Islam. Jakarta: Pustaka Alfabet, 2011.

Badudu, J. S, Zain, Sutan Mohammad. Kamus Umum Bahasa Indonesia, Jakarta :Pustaka Sinar Harapan. 2001.

Bakry ,Noor M. Pancasila Yuridis Kenegaraan. Yogyakarta:

Liberty. 1994.

Fajar, M. Ilmu Komunikasi Teori Dan Praktik. Yogyakarta:

Graham Ilmu. 2009.

Fuad, Ahmad Nur, dkk, Pendidikan Kemuhammadiyahan. Sidoarjo: UMSIDA Press. 2012.

Jainuri, Achmad. Ideologi Kaum Reformis; Melacak Pandangan Keagamaan Muhammadiyah Periode Awal. Surabaya: LPAM, 2002.

Lewis, Bernard. What Went Wrong: The Clash Between Islam and Modernity in the Middle East. London: Weidenfeld \& Nicolson, 2002.

Maarif, A. Syafi'i. Islam Kekuatan Doktrin dan kegamangan Umat. Yogyakarta: Pustaka Pelajar, 1997.

Nasir, Haedar. siaran pers tanggal 2 Agustus 2017 di Jakarta. 
PP Muhammadiyah, Negara Pancasila Sebagai Darul Ahdi Wa Syahadah; Muktamar Muhammadiyah ke 47 di Makasar Yogyakarta: Gramasurya, 2015.

PP Muhammadiyah, Pedoman \& Panduan Lazizmu; Memberi Untuk Negeri.

Tim Kerja Tindak Lanjut Kerja sama dengan PP Muhammadiyah dan Kemenko PMK 


\section{Profil Penulis}

Anita Puji Astutik, lahir di Sidoarjo pada tanggal 21 Januari 1980. Dosen tetap Universitas Muhammadiyah Sidoarjo yang mengampu mata kuliah Al-Islam dan Kemuhamadiyahan dan mata kuliah Pendidikan Agama Islam ini memperoleh gelar kesarjanaan dari Fakultas Tarbiyah jurusan Pendidikan Agama Islam Institut Agama Islam Negeri Sunan Ampel Surabaya dengan predikat Cumlaude (2001). Aktifitas sosial keagamaan di organisasi Aisiyah dan partisipasi di tengah masyarakat serta menjadi praktisi di dunia pendidikan tidak melupakan dahaganya dengan dunia akademis, dengan melanjutkan ke jenjang Pasca Sarjana Universitas Muhammadiyah Sidoarjo. Gelar M.PDI dari Universitas Muhammadiyah Sidoarjo diperoleh dengan predikat Cumlaude pada tahun 2013.

Aktivitas menulis terus dilakukan untuk mencegah kebuntuhan idealismenya. Selain menghasilkan karya tulis diberbagai media, juga berkontribusi sebagai penulis buku ajar. Diantara hasil karya yang sukses diterbitkan antara lain 
Fullday School, Sebuah Pilihan? (2016), Islam dan Ilmu pengetahuan bidang kesehatan (2016), Islam dan Ilmu Pengetahuan bidang Ilmu Sosial dan Ilmu Politik (2017) dan Metodologi Studi Islam dan Kajian Islam Kontemporer Perspektif Insider/Outsider (2018). Kehausannya akan keilmuan tentang Islam mengantarkannya kembali ke bangku perkuliahan Konsentrasi kajian Islam Kontemporer pada tahun 2017 dalam studi S3 di Universitas Islam Negeri Sunan Ampel Surabaya. 
18日N 978-623-7578-65-9

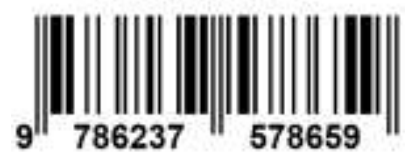

WAWASAN KEBANGSAAN:

NEGARA PANCASILA SEBAGAI DARUL 'AHDI WA AL SYAHADAH 